Cavicornia, in being independent ossifications, situated, on the suture between the frontal and parietal bones instead of simple outgrowths from the frontal only. A median excrescence on the forehead, in front of the above-mentioned processes, is the result of a protrusion upwards of the bones in the part.

The Pronghorn (Antilocapra) has well-developed horns. They are attached to ordinary bony cores, exactly similar to those of the Antelopes. They are, however, unique of their kind in that they are branched or bifurcate at their tips, a second smaller point springing from the anterior margin of the flattened stem, and running forward with a gentle curve, convex upwards. In another respect these horns are even more peculiar. Mr. Bartlett, the Superintendent of the Society's Gardens, was the first to show, from a specimen living in the Gardens, that the Pronghorn is in the habit of annually shedding its horns from off their cores. This surprising discovery has since been fully confirmed; at the end of each season the core being found covered with a skin from which the fresh horn is developed.

Respecting the geographical distribution of the Cavicornia, none are to be found in Australasia or in South America. Very few inhabit North America; the Bighorn Sheep, one of the Bisons, the Musk Ox, the Mountain Goat, and the Pronghorn embracing them all. Africa is the head-quarters of the sub-order, and specially of the Antilopine family. In Europe the Bison is a native of Poland, the Chamois and the Ibex of the Alps; whilst the peculiar Saiga reaches our side of the Caspian Sea. Among the best known Indian Antelopes are the Sasin or Antelope par excellence, and the Nilghau,

The Chevrotains, or Tragulidæ, form a group of small, deer-like animals, without horns, which were formerly associated with the Musk Deer. The investigations of Prof Flower have, more than any others, proved the independent nature of the group, which approach in their internal anatomy to the Pigs. The third stomach of other Ruminants-the Psalterium-is wanting. In the axis vertebra, the odontoid process, instead of being scooped into a spout, as in the Deer and Antelopes, is peg-like, as in the Swine. The second and fifth metacarpal bones are completely developed from end to end, and the lateral marginal intervals of the upper jaw between the canine and molar teeth are not cut away, as they are in other Ruminants. These and other peculiarities in the teeth, \&c., are quite sufficient to divide off the sub-order as an independent one, ranking with the others previously described. The number of genera and species are very inconsiderable, there being two of the former (Hyomoschus and Tragulus), and not half a dozen of the latter. Hyomoschus inhabits Western Africa, occupying much the same ground as does the Chimpanzee. In it the metacarpal bones remain separate during the life of the animal, as in the Swire, and not in the other Ruminants. The fur is spotted like that of most young deer, throughout life. Tragulus is found, two species-T. meminna and $T$. stanleyanus - in India, the Napu (T.javanicus) and one or two others making Java and Sumatra their abode.

$$
\text { (To be continued.) }
$$

\section{RARE ANIMAL AT THE MANCHESTER AQUARIUM}

AONG the numerous new accessions brought toA gether to swell the list of special attractions for the throngs of Whit-week visitors at the Manchester Aquarium, one of the latest arrivals is especially deserving of notice in these columns. This is an example of the so-called "Congo Snake" (Murש̌nonsis tridactvla), from the neighbourhood of New Orleans, a singular eel or snake-like arimal, belonging, nevertheless, to neither of the classes represented by those two types, but rather to the true Amphibia. Judging from its shape, proportions, and colour, the uninitiated would certainly pass it as an ordinary eel, from which, on closer examination, it will be found to differ in possessing no fins, small bead-like eyes a mere puncture in the place of the ordinary gilloperculum, though more especially in having stationed at each extremity of the attenuated body a pair of feeble little legs, and each leg furnished with three slender toes. These legs may be described as almost rudimentary, but they are at the same time used by the animal, and with more marked effect than might be presupposed, when crawling over the ground at the bottom of its tank. Rising into the midst of the water, it can further swim with great rapidity, progressing then by rapid undulations of its body from side to side, after the manner of a true snake. The length of this specimen is about two feet six inches; greatest diameter, in the centre of the body, one inch and a half, tapering off from the posterior pair of legs into an attenuate and slightly compressed tail. The colour closely resembles that of an ordinary eel, being slate-grey on the dorsal surface and sides down to the lateral line, and below this, ash colour. Along the lateral line is a double row of minute punctures, the orifices, no doubt, of mucous glands similar to those obtaining in true fishes. The animal has to repair to the surface of the water to breathe, but this is at distant intervals, a large quantity of air being drawn through the nostrils into the lung-pouch by a singular inflation of the throat, repeated several times in succession. This specimen is exhibited in one of the octagon table tanks in the centre of the saloon, eighteen inches in depth, so that when taking in its supply of air it does not altogether leave the ground, but raises itself in a semi-erect position until the head touches the surface of the water. With the head just an inch or two below the surface, and standing, as it were, upon its posterior legs, with the anterior pair held out helplessly in the water, is a very favourite attitude with this creature, though at the same time an essentially grotesque one, reminding the observer of the somewhat similar attitude and general appearance, on a colossal scale, of the larva of Ourapteryx or other of the Geometria moths. In its native swamps the "Congo Snake" is reputed by the black population to be highly venomous, an injustice to the poor creature as great as when applied by our own benighted countrymen to the harmless Newt or Triton of English ponds and streams, and of which it is merely a highly interesting and most extraordinary exotic type.

We are indebted for this rare and, indeed, at present, we believe, in this country, unique example of this species to Capt. A. H. Mellon, of the Dominion and Mississippi Steamship Company, to whose influential and friendly assistance we are also under further obligations for a fine young alligator some two feet long, the trophy of a preceding voyage.

W. SAVILIE-KENT

\section{THE PROGRESS OF THE TELEGRAPH *}

\section{$\mathrm{VI}$.}

T has already been observed that from the limited speed on the wire, the development of any extended system of telegraphic communication between the centres of commerce in a country where great distances have to be reached, involves a vast outlay in the duplication of the circuits necessary to afiord the requisite transmitting powers, and that by the adoption of the automatic process, in addition to the accuracy of its performance, the greater speed obtained upon long circuits enabled the telegraphic service to be conducted by a much smaller number of wires, thus reducing in a most important degree the outlay of capital expended oin con-

\footnotetext{
* Continued from po 32
} 
struction. It is not, however, only by the automatic process that the full transmitting capacity of a conducting wire can be attained. Metallic conductors under certain conditions are capable of transmitting more than one current at the same instant of time, both in the same and in opposite directions; and by a very ingenious system of adjustment of electric resistances and balance of currents, perfected by Messrs. Stearns, Edison, and Prescott, the American electricians, intelligence can be transmitted and recorded over a single wire in opposite directions at the same moment. This system of transmission is known as "Duplex", and "Quadruplex" Telegraphy, and is already extensively employed by the Western-Union Telegraph Company in the United States, and over several of the more important circuits in Great Britain. The "Duplex" system is working in America between nearly all the principal cities, and has recently been in troduced between Port Hastings, on the island of Cape Breton, where the land circuits are in connection with the submarine cables, and San-Francisco, a distance little short of 5,000 miles. The "Quadruplex" system. has been successfully introduced between New York and Boston, with a transmitting capacity upon a single wire equivalent to the transmitting power of four wires worked upon the ordinary Morse system. Thus, by employing arrangements such as the "Duplex" and "Quadruplex," a circuit may be worked either as one wire, or two, three, or four wires, according as the transmitting capacity of the circuit may require to be increased.

As is well known, several sounds may be conveyed at one and the same time by vibrations through a rod without interference, and it is difficult to realise the accuracy with which every vibration is reproduced by anyone who has not witnessed an illustration of the "transmission of sound "by solid conductors. So it is with "Duplex" and "Quadruplex" transmissions through the same wire in opposite directions at the same moment of time; it is equally difficult to realise how distinct signals can be received at either end without interfering with or destroying each other; and yet the principles involved are very simple and easy of explanation.

By the Duplex system, one of the most difficult problems incident to the successful development of telegraphic lines has been solved, namely, how to provide for the annual increase (averaging 20 per cent.) in the amount of business without the annual expenditure on capital account for the erection of additional wires. In the United States, over 150,000 niles of wire are in operation, the rate of increase being something like 20,000 miles per annum, and the Duplex system is capable of doubling the carrying capacity of these wires. The great value of the Duplex system consists in its capability to double the capacity of a wire at any moment, should injury by storm or conflagration interrupt the circuits. By its means, the moment one wire is restored to continuity it becomes equivalent to two, and a second wire raises the carrying capacity of the circuits to four wires, and by skilful manipulation the system may be introduced and adjusted on a circuit in about a minute. From the earliest days of telegraphy it has been well known that two currents, either in the same or in opposite directions, could be passed simultaneously through a conducting wire; indeed, by this means, often has the frame of mind and temper of the operator at the distant station been clearly read at the receiving station, even though situated some hundred miles distant. When the direction of the currents from the two stations are passed into the wire in the same direction, the directive force of the needle becomes more decided, and when the direction is contrary the motion of the needle will be comparatively neutralised and scarcely perceptible. The effect of a current transmitted along a wire from one station upon a'galvanometer needle while currents are being transmitted from anotner station has therefore been long known. How this circumstance has been applied to the indication of distinct signals will now be explained.

Let us suppose two stations, $A$ and $B$, are to beconnected for signalling each other upon the Duplex system : the action of the coils in the instruments at the respective stations is so arranged that neither station's local or outgoing current shall affect its needle when passed into the line, its dial being left free to indicate the effects produced by the incoming current from the distant station. For this purpose it is necessary to wind the coils of the instruments with two parallel wires after the manner of a differential galvanometer. Now, as is well understood in testing a line wire for resistance between two stations with a differential galvanometer, until the artificial resistance interposed has been made equal to that of the line to be tested, the battery current passed by the key into the galvanometer will move the needle in the one direction if the artificial resistance is too small, and in the other direction if the resistance is too great. It is only when an accurate balance is obtained-that is, when the two resistances have been made equal - that a current will not move the needle, because then the current is equally divided between the coil connected with the artificial resistance and that connected to the line, which two coils being wound in opposite directions counteract one another. Thus, so long as the artificial resistances (rheostats) at each end of the line are equal to that of the circuit, each station will see the current sent by the other, while neither station will see upon his own instrument the current he is passing into the line; and for this reason, that the currents sent by each station divide equally between the line and the rheostat, passing through the coils in opposite directions, and have therefore no effect upon the needle of the sending instrument. When the distant station sends a current, it either increases or diminishes the effect of the home current ; in the first case, it augments that portion which passes through the coil connected to the line, so that more flows into the line than into the rheostat, and the needle moves. In the second case, it reduces the current flowing to the line, and more will flow through the rheostat, moving the needle in an opposite direction. Thus it is seen that the two currents do not pass one another, but that when both stations signal at the same time, the current sent by either of them acts upon the distant instrument by determining whether the currents sent by that station shall pass through the line or the rheostat. Thus we see that when station $A$ signals separately, the current is equally divided in passing through its instrument coil, and its effect is neutralised upon the needle, but it passes through both coils of the distant instrument in the same direction, and therefore produces a signal. If both $A$ and $B$ depress their contact keys at the same moment, the currents from the two batteries are united so far as the line wire is concerned, and this produces an effect upon the differential arrangements at each equivalent to a lessening of the resistance of the line, and therefore more current flows to the line than through the rheostat. It is thus seen that the Duplex system affords a means of increasing the transmitting capacity of a wire ; and an invention which practically converts one wire into two, three, or four, as the necessities of business may require, is of great value.

A short historical summary of the introduction and progress of the electric telegraph, from its earliest application in a practical form to the establishment of its present world-wide reputation and utility, will be naturally of interest to the general reader; and the following short sketch may convey in a succinct manner the step by step progress that year by year has registered the index of improvement. It is not intended in any way to make the present sketch personal: some well-known names must of necessity be referred to, and the reader should also 
be informed that the narrator in this instance has personally been more or less connected with the progress of the telegraph from 1844 , the date at which this story commences, to 1875 , the period under review. In the year first mentioned Charles Wheatstone, Professor of Natural Philosophy at King's College, London, was at the same time connected with a musical instrument and publishing business in Conduit Street, Regent Street. In that house many of his important improvements and patents in connection with the electric telegraph were carried out, and many of the drawings connected with the filing of the specifications of those patents were, by permission of the directors of the East and West India Dock Company, elaborated by a clerk in the Dividend Office of the Dock House, Billiter Square ; resolutions standing in the Minute Book of the Dock Board authorising the devoting of his spare time in the office to $M r$. Wheatstone's telegraph drawings, and afterwards a resignation in favour of an appointment in the then projected Electric Telegraph Company.

Prefaced with these preliminary remarks, the more immediate subject matter of the present paper will be commenced. It is a matter of history that the early telegraph patents of Cooke and Wheatstone were disposed of for a sum of I20,000l. to a Company called the Electric Telegraph Company, in which the late John Lewis Ricardo, M.P. for Stokeupon-Trent, was at once the mainspring and vital elemerit. Of this amount Cooke retained $00,000 l$., and Wheatstone received 30,000 . This sum included the transfer to the Company, besides other matters, of the telegraph line between Paddington and Slough, on the Great Western Railway, already alluded to in the earlier pages of this summary. As already mentioned, this short line was a kind of Madame Tussaud-daily advertisements, and a profusion of visitors entertained, or, as they imagined, duped or bamboozled, at one shilling a head, into the belief that standing before the little instrument in the Paddington station, it would there and then convey their thoughts, and in intelligible language return a response from a station some twenty miles distant. Inquiries as to the "time of day" "state of weather," or general health of the operator, served to test the accuracy of the new invention. Nevertheless, nine out of every ten persons who were attracted by the printed placards sown broadcast about the station, left the Paddington terminus as little impressed with any belief that what they had seen represented the future germ of a great invention, as if they had viewed the automaton chess player. Necromancy, witchcraft, and delusion seemed to be the parting impression on their minds as they left, in return for their shilling charge. The announcement as issued in 1844 , inviting the patronage of the public, is here reprinted; it affords an amusing souvenir of the early history of the telegraph :-

\section{[Facsimile of Antouncement.] "Under the Special Patronage OF ROYALTY.}

INSTANTANEOUS COMMUNICATION between Paddington and Slough, a distance of nearly twenty miles, by means of the ELECTRIC TELEGRAPH,

which may be seen in operation Daily, from nine in the morning till eight in the evening at the

Great Western Raitway, Paddington Station, and the Telegraph CotTage, close to the Slough Station. Admission-One Shilling, Children and Schools halfprice.

Since this very interesting Exhibition has been opened to the Public, it has been honoured by the visits of His Royal Highness Prince Albert, the Emperor of Russia, the King, and Prince William of Prussia, the Duke de Montpensier, His Royal Highness the Duke of Cambridge, the Duke of Wellington, Sir
Robert Peel, the Foreign Ambassadors, and most of the nobility, \&c.

"In no way has the science of Electricity been made so subservient to the uses of man, as in its application to the purposes of Telegraphic Communication, which is now brought to the height of perfection. The working of this beautiful apparatus is not in the least degree affected by the weather, intelligence can be sent by night equally well as by day; distance is no object; by its extraordinary agency communications can be transmitted to a thousand miles in the same space of time, and with the same ease and unerring certainty, as a signal can be sent from London to Slough. According to the best authorities, the electric fluid travels at the rate of 280,000 miles in a second.

"The Electric Telegraph has been adopted by Her Majesty's Government, and the Patentees have just completed a line of communication between London and Portsmouth, agreeably to directions received a short time ago from

THE RIGH'T HONORABLE THE LORDS OF THE ADMIRALTY.

"In the late trial of John Tawell, at Aylesbury, for the murder at Salt Hill, near Slough, the Electric. Telegraph is frequently mentioned in the evidence, and referred to by Mr. Baron Parke in his summing up. The Times newspaper very justly observes ' that had it not been for the efficient aid of the Electric Telegraph, both at the Paddington and Slongh stations, the greatest difficulty, as well as delay, would have been occasioned in the apprehension of the prisoner.' Although the train in which Tawell came to town was within a very short distance of the Paddington Station before any intelligence was given at the Slough Telegraph Office, nevertheless, before the train had actually arrived, not only had a full description of his persou and dress been received, but the particular carriage and compartment in which he rode were accurately described, and an officer was in readiness to watch his movements. His. subsequent apprehension is so well known, that any further reference to the subject is unnecessary.
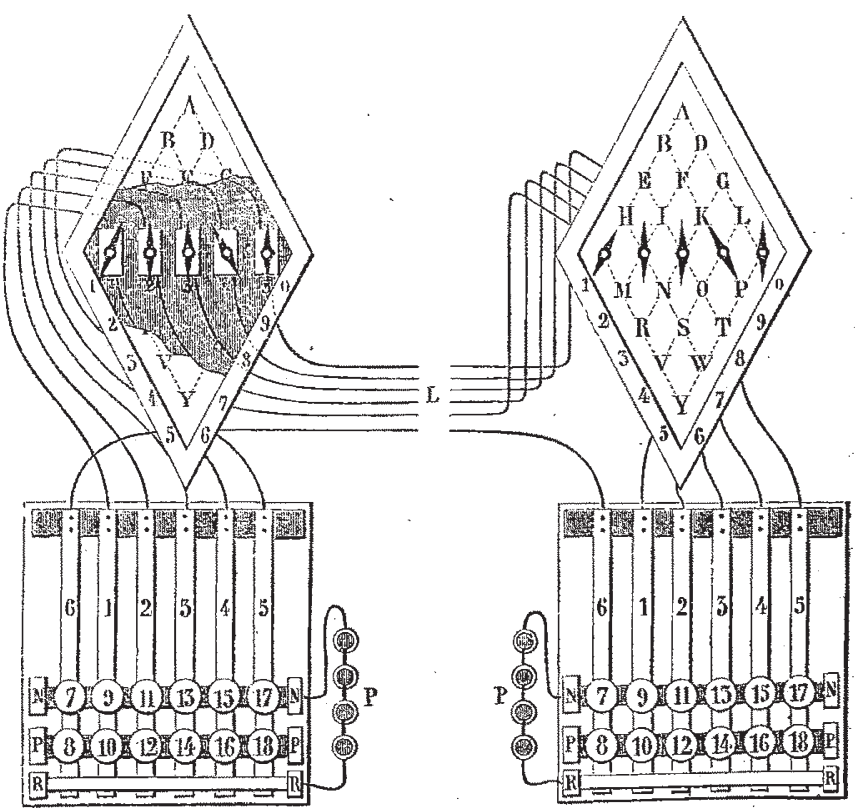

Fig. 26.-Cooke and Wheatstone's five-needle telegraph.]

"The Telegraph Office at Paddington Station is at the end of the Up-train Platform, where a variety of interesting apparatus may be seen in constant operation."

The first office of the Electric Telegraph Company was at 345 Strand, a site now occupied by the Gaiety Theatre. In those days ( 1846 ) scientific men of renown crowded the instrument room to witness the progress of this great invention: George Stephenson, the Astronomer Royal, Brunel, Vignoles, G. P. Bidder, Samuda, Rennie, Fairbairn, and most of the leading engineers of the day. In 
345, Strand, the magnetic disturbances and interference with transmitted signals from aurore and earth-currents were first observed and the observations tabulated, which have since proved useful, notwithstanding the then defective construction of the recording apparatus; here also the earliest lines of railway telegraph were inaugurated; the long five-inch astatic combination of the double needle

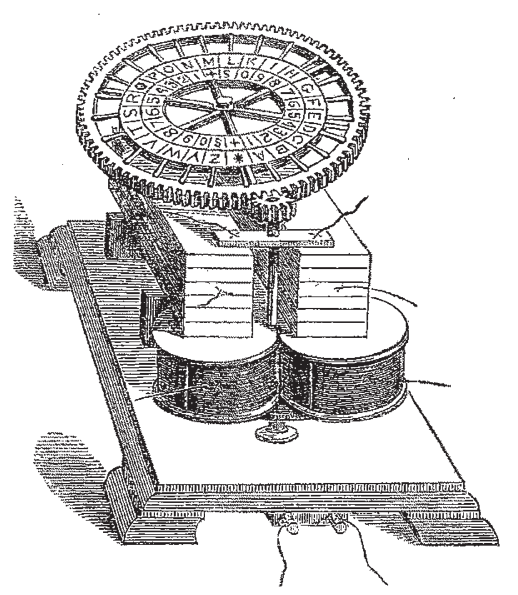

and single needle instruments was employed, taking the place of less perfect apparatus. It must be remembered that, previous to the introduction of the double and single needle instruments, very cumbersome apparatus had been employed. There was the five-needle instrument, requiring five wires for the five needles, and a sixth wire for the return current (Cooke and Wheatstone's patent, 1837);

Fig. 27,- Wheatstone's letter-showing dial telegraph, $x 840$.

the respective letter or signal being indicated by the concurrent deffection of two pointers. Obviously, this instrument became useless for extended circuits, the eapital cost of outlay for the six wires restricting its use. The old letter-showing apparctus of Cooke and Wheatstone (1840), in which the letters of the alphabet composing the word are severally presented to view at an opening in a dial-plate by means of an electro-magnet acting upon the pallets of an escapement, put in motion by inde-

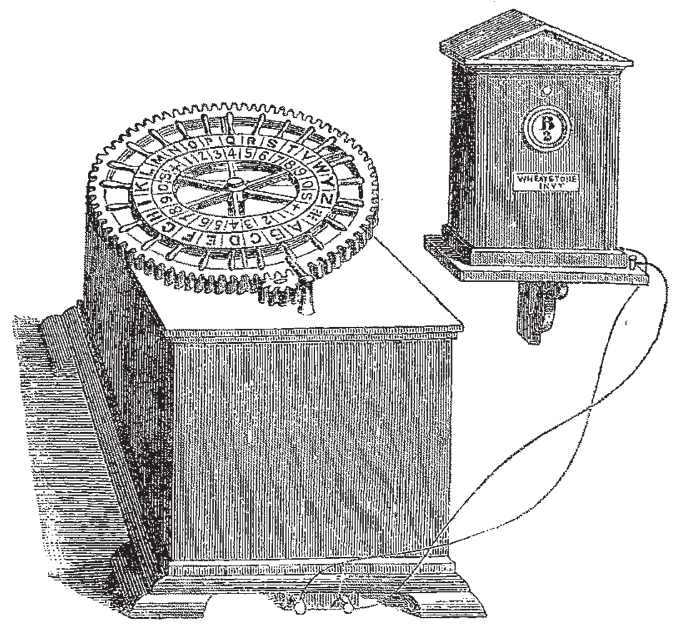

pendent clockwork. The communicator of the instrument is furnished with a dial-plate similar to that of the indicator, so that on the rotation of the dial of the communicator by the operator, the necessary succession of make and break currents of electricity are sent through the wire and controlled so as to actuate the motion of the indexpointer of the indicator at the distant station.

(To be conimued.)
THE TNDIAN TRTGONOMETRTCAL SURVEY* $\mathrm{NE}$ does not usually expect to find much of general interest in the Report of a Trigonometrical Survey. Col. Walker's admirably drawn-up Report, however, includes some matter of more than special value; indeed, many of the details connected with the immediate work of the Survey are calculated to interest the general reader, they are concerned to such a large extent with the peculiar difficulties to be overcome by the various parties, difficulties which make ordinary survey work look like mere child's play.

The Index Chart prefixed to the Report enables one to form a very full idea of the work which has already been done, and of how much there is yet to do. From Cape Comorin to Peshawur and all along the Himalayan frontier, and from Kurrachee on the west to Burmah on the east, the country is covered with an intricate net-work of triangulation, including, ilowever, many gaps which will take many years to fill up. Shooting out from the northern border of the system of triangulation are numerous aurora.like lines indicating the secondary triangulation to fix the peaks of the Himalayan and Sooliman ranges. We cannot go into the details of the work of the Survey, and must content ourselves with a brief summary of the out-turn of work during the year under review, and with a reference to a few of the more interesting side topics.

Of Principal Triangulation, with the great theodolites of the Survey, seventy triangles, embracing an area of

* General Report of the Operations of the Great Trigonometrical Survey of India, during $1873-74$, by Col. J.T. Walker, R.E., F.R.S., Superintendent of the Survey (Dehra Dun; Office of the Superintendent, G.T. Survey, M. J. O'Comnor, 8874 .)
7,190 square miles, and disposed in chains which, if united, would extend over a direct distance of 302 miles, and in connection with which three astronomical azimuths of verification have been measured. Of Secondary Triangulation, with vernier theodolites of various sizes, an area of 5,212 square miles has been closely covered with points for the topographical operations, an area of 3,650 square miles has been operated in pari passu with the principal triangulation but exterior thereto, and in an area of 12,000 square miles - in the ranges of mountains to the north of the Assam Valley which are inhabited by independent tribes-a large number of peaks have been fixed, many of which have already been found serviceable in the geographical operations now being carried on with the military expedition against the Dufflas. Of Topographical Surveying, an area of 534 square miles has been completed in British portions of the Himalayas, on the scale of one inch to the mile, an area of 2,366 square miles in Kattywar on the two-inch scale, and areas of 690 and 63 square miles respectively, in Guzerat and in the Dehra Dún, on the scale of four inches to the mile. Of Geographical Exploration much valuable work has been done in Kashgharia and on the Pamir Steppes, in connection with Sir Douglas Forsyth's mission to the Court of the Atalik Ghazi, and several additions to the geography of portions of Great Thibet and of Nepaul have been obtained through the agency of native explorers.

In the course of the operations of the year under review the northern section of the Brahmaputra Meridional Series has been completed, whereby two important circuits of triangulation formed by it with the Assam and East Calcutta Longitudinal Series to the north and south, the Calcutta Meridional and the Eastern Frontier Series to 